\title{
Fuzzy Logic Implementation of Vulnerability Assessment in a Coastal Aquifer of Northern Sicily
}

\author{
Antonio Cimino ${ }^{1}$, Adolfo Cimino ${ }^{2}$, Antonino Oieni ${ }^{3}$ \\ ${ }^{1}$ Department of Physics, University of Palermo, Italy \\ ${ }^{2}$ Consultant Geologist, Sicilian Geologist Association, Cammarata, Italy \\ ${ }^{3}$ Consultant Geologist, Sicilian Geologist Association, Tusa, Italy \\ Email: antonio.cimino@unipa.it, adolfocimino@virgilio.it, oieniantonino@gmail.com
}

How to cite this paper: Cimino, A., Cimino, A., \& Oieni, A. (2021). Fuzzy Logic Implementation of Vulnerability Assessment in a Coastal Aquifer of Northern Sicily. Journal of Geoscience and Environment Protection, 9, 177-188.

https://doi.org/10.4236/gep.2021.98012

Received: July 23, 2021

Accepted: August 23, 2021

Published: August 26, 2021

Copyright $\odot 2021$ by author(s) and Scientific Research Publishing Inc. This work is licensed under the Creative Commons Attribution International License (CC BY 4.0).

http://creativecommons.org/licenses/by/4.0/

\begin{abstract}
Aquifers can be defined as complex ecological systems. Their description is closely influenced by geometrical and geological parameters, which portray the hydrogeological behaviour of underground systems. This paper reports a contribution to assessing groundwater contamination risk in a particular Sicily sector, where deterministic approaches have methodically assessed and mapped vulnerability and quality of groundwater. In detail, in the coastal area of Acquedolci (Northern Sicily), already intensely surveyed in the frame of interdisciplinary projects on geological risk, implementing models and systems have been experimented, also considering fuzzy logic. Cartography issues are here presented and compared, with particular regard to the effect of stochastic hydrogeological elements (i.e. "depth to water"), locally characterized by variability for simultaneous climate, overdraft, irrigation and sea encroachment. The authors show how fuzzy logic, applied to vulnerability settings, contributes to a better comprehension of the passive scenery offered by aquifers in Acquedolci Sicily area.
\end{abstract}

\section{Keywords}

Fuzzy Logic, Groundwater Vulnerability, Acquedolci Plain, SINTACS Method, Pearson Correlation Coefficient

\section{Introduction}

It is universally acknowledged that mapping of hydrogeological risk to contamination constitutes an essential management tool of the territory (Baalousha, 2010). Its elaboration, for a long time encouraged by the scientific world and 
prescribed by recent laws, uses advanced technical and computerized methodologies (Zuquette et al., 2009). Production and implementation of such cartographies demand an elevated number of data and the engagement of multidisciplinary skills, represented by professional and operating investigators in many earth science matters, like geochemistry and geophysics (Cimino et al., 2008). These requirements rigorously need a high accuracy degree, especially in cases of certain aquifers, defined as complex ecological systems (Wu \& David, 2002). Their representation is deeply affected by geometrical and geological parameters, depicting, on the whole, the hydrogeological behaviour of groundwater.

This is the case of various Sicily areas, where vulnerability parameters as depth to water can be subjected to stochastic variability. As matter of fact, simultaneous considerations of deterministic and statistical approaches allowed us to improve the assessment of the hydrogeological risk to contamination (Panagopoulos et al., 2006) utilizing and implementing models and systems already experimented (for example, the point-count systems ones). In particular, pollution vulnerability and diffusion properties of contaminants relevant to porous aquifers can be usefully estimated, considering fuzzy logic. This important tool is used to perform a more consistent study of the values of parameters concerning aquifer vulnerability in a certain territory, starting from a classic methodology, i.e. the DRASTIC one (Di Martino et al., 2005).

The authors propose, in this paper, an approach towards the vulnerability assessment of the Acquedolci hydrogeological systems (Northern Sicily), simply comparing different vulnerability and contamination cartography issues. Goal of this research, as for similar works carried out in contiguous coastal areas of Sicily, is to propose an essential tool for correct managements of groundwater in crowed regions, where agricultural, tourist and urban needs are growing with time (Cimino et al., 2000).

\section{Deterministic and Probabilistic Approaches in Applying Vulnerability Assessment Methods}

\subsection{Groundwater Vulnerability Assessment}

Vulnerability assessment is generally characterized by uncertainties, due to the subjectivity in applying the numerous standards overall proposed in these last decades (Abdullah et al., 2017). The exigency to reduce them in parameterization of pollution groundwater vulnerability was very felt, especially in complex aquifers (Ducci, 2010).

The hydrological features of territory as the surveyed one usually exhibit a certain steadiness against their perturbation, unless a determinate threshold is overcome. Then, the return towards a primitive condition can be seriously prevented, with a deep modification of the water system. In this specific context, the intrinsic vulnerability concept, when referred to an aquifer system, resumes an elevated number of elements, with a relative difficulty of its comprehensive knowledge. This causes a relative vagueness in representing the aquifer's weak- 
ness. Furthermore, the vulnerability concept, in spite of its numerous expressions, cannot avoid a stochastic approach, imposing its profound review.

As matter of fact, outcomes of different vulnerability methods, when experimented in the same area, exhibit notable differences. Many Authors suggested the simultaneous application of diverse methodologies, comparing the relevant results and discussing them in order to improve the tested procedures. This paper, starting from the Italian SINTACS system (Civita \& De Maio, 2000), proposes new approaches to implement the knowledge of hydrogeological complex systems of Northern Sicily. Thus, the fuzzy approach can mitigate problems of ambiguity originating from the standard application of vulnerability assessments (Cameron \& Peloso, 2005). Fuzzy logic takes into account the natural stochastic variability of vulnerability factors, including background noise levels and eventual errors in sampling and measuring procedures.

Groundwater vulnerability assessment can be faced in different ways, grouped in two main categories: The former one directly classifies aquifers in typological classes; the latter indirectly assesses vulnerability by ratings, scores or indexes. In this last case, the rigorous and sometimes artificial subdivision of parameter values in sharp classes as in the SINTACS method denies their possible variations, so resulting in an excessively severe simplification and a strong limitation to take into account their reciprocal relations. In fact, hydrological phenomena usually present non-linear relations, strictly related to perturbations of the fundamental process, suggesting to go towards the application of the fuzzy logic, that overcome the simple bivalence of the true or false decisions.

The authors show some relatively simple ways to solve the exposed problems, choosing one of the most contaminated and crowded plains of the whole coastal belt of northern Sicily. The aquifers hosted in the Acquedolci selected area are well known through the very numerous integrated surveys and the scientific contributions by interdisciplinary research groups. In detail, University of Palermo in the ambit of interdisciplinary studies (Cimino et al., 2008), also for the following, performed several geological, geochemical and geophysical surveys, on the basis of necessary preliminary knowledge of the region.

\subsection{The Study Area}

Acquedolci coastal plain is located in the Northern coast of Sicily (Figure 1), and is bounded by Tyrrhenian Sea on the North, a group of steep relieves on the South, and by Inganno and Furiano Torrents on the East and West respectively. It is principally constituted by: 1) Quaternary alluvial deposits, with various permeability degrees in accordance with its granulometry and hosting a sandygravelly-arenaceous unconfined aquifer; 2) A Mesozoic calcareous-dolomitic complex, with secondary permeability for fractures and karst (San Fratello Mt.), forming a conspicuous depth aquifer below the plain, with an irregular groundwater circulation and a large exposition to pollutants; 3) A Tertiary clayey-marlyarenaceous complex, including all the deposits belonging to flysch units; it exhibits 

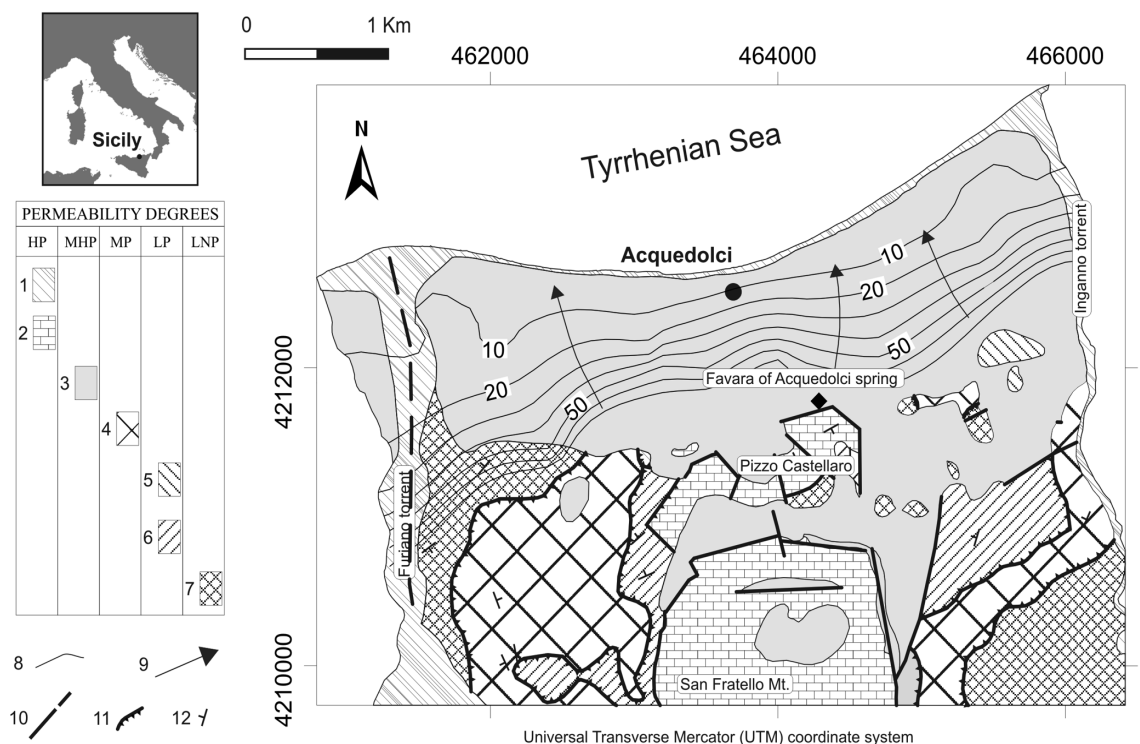

Figure 1. Hydrogeology of Acquedolci plain (Northern Sicily). 1: High permeability (HP) for porosity (detritus, alluvial deposits); 2: High permeability $(H P)$ for fractures and karst (limestones); 3: Medium-high permeability $(M H P)$ for porosity (fluvial-marine terraces); 4: Medium permeability $(M P)$ for porosity and fractures (flysch); 5: Low permeability $(L P)$ for porosity (lacustrine deposits); 6: Low permeability $(L P)$ for porosity and fractures (marly limestones); 7: Low or null permeability (LNP) (flysch and metamorphites); 8: Groundwater contour lines (m a.s.l.); 9: Groundwater drainage axes; 10: Faults; 11: Thrusts; 12: Strikes and dippings (Cimino et al., 2008).

low or very low permeability. These hydrogeological units show a generally high permeability, mainly in the sandy-arenaceous littoral belt and in the alluvial fans. Clayey formations heavily influence groundwater circulations and calcareous-dolomitic outcrops supply the calcarenite aquifer (Figure 1).

In spite of this apparent homogeneity of granulometry and permeability of the outcropping formations, the corresponding aquifers exhibit a diffuse anisotropy in localized sectors, confirmed by field data picked up and analyzed in successive inventories.

A deterministic approach has been preliminarily executed by assessing the transitory maps relevant to the SINTACS standardized method (Civita \& De Maio, 2000). The seven parameters were elaborated using numerous data records collected during several fields and inventories. Dynamic archives were produced in GIS environment, obtaining an agile tool to carry out vulnerability maps. This first step appeared to be unsatisfactory, due to unavoidable time variability in some elements and their consequent difficult estimation and control (Cimino et al., 2010). As an example, depth to water results are affected by a fair changeability in different sectors of the Acquedolci plain, strictly depending on anthropic and natural events due to geological and territorial causes. Thus, the careful attention of probabilistic elements is usually recommended in these specific works, also overcoming the problem of lacking in drilled wells and in stratigraphic data with geophysical surveys: These ones played a decisive role in the characteriza- 
tion of complicated sectors of Acquedolci.

\subsection{The SINTACS Method and Its Modification}

The SINTACS method was intensely applied in coastal areas of Sicily with the aim to offer a quantitative evaluation of the groundwater pollution vulnerability (Cimino, 2005). This is a fully computerized methodology, suggested by the Italian National Research Council-CNR. SINTACS is derived by the U.S. DRASTIC system (Aller et al., 1987), through successive integrations and modifications. GIS software allows to discretized the investigated area with a grid of square finite elements and to perform a set of seven maps, relevant to these hydrogeologically significant parameters: Depth to water, Net recharge, Unsaturated zone, Soil cover, Aquifer characters, hydraulic conductivity and Slope. Ratings and weights are assigned to SINTACS parameters in relation to different identified situations. For each cell of the grid format, the vulnerability index $I_{v}^{n}$ is defined by the following summation:

$$
I_{v}^{n}=\sum_{j=1}^{7} P_{j} \cdot W_{j}^{n}
$$

where $P_{j}$ is the rating relevant to the $j^{\text {th }}$ parameter proposed in the system, $W_{j}^{n}$ the weight and $n$ the selected string assigned to each cell. Weights are assigned taking into account five different hydrogeological and/or impact situations (Cimino et al., 2000) (quoted paper).

In the Acquedolci studied region, intrinsic vulnerability mapping has individuated the most vulnerable zones in the alluvial fan and in a relatively narrow belt along the coastline.

With the aim to successively propose a statistical elaboration, the authors suggested firstly reduce the number of SINTACS parameters, so elaborating a renewed vulnerability cartography. Only Depth to water, Net recharge, Hydraulic Conductivity and Slope concur to this new set of parameters, here named SICS Release from the former Italian SINTACS acronym. The chosen parameters correspond to the most unfavorable values, conditioning higher vulnerability scores. This permits a precautionary scenery, furtherly preventing against possible underestimations (Cameron \& Peloso, 2005) (quoted paper). Even if soil covering can play a good protective role for aquifers, it was neglected to analyze parameter consistency through several transition trials. This was done by comparing, using the Pearson correlation coefficient $r$, couples of all parameters each other in different test areas of Italy (Cimino et al., 2010). Thus, soil parameter statistically presented a fair dependence with respect to the other ones.

The results of SICS cartography advancement are mapped in Figure 2. Here, more vulnerable zones are localized in alluvial and fluvial-marine terraces (at North), in detritus and limestones (at South). Lower vulnerability values are offered by flysch and metamorphites. 


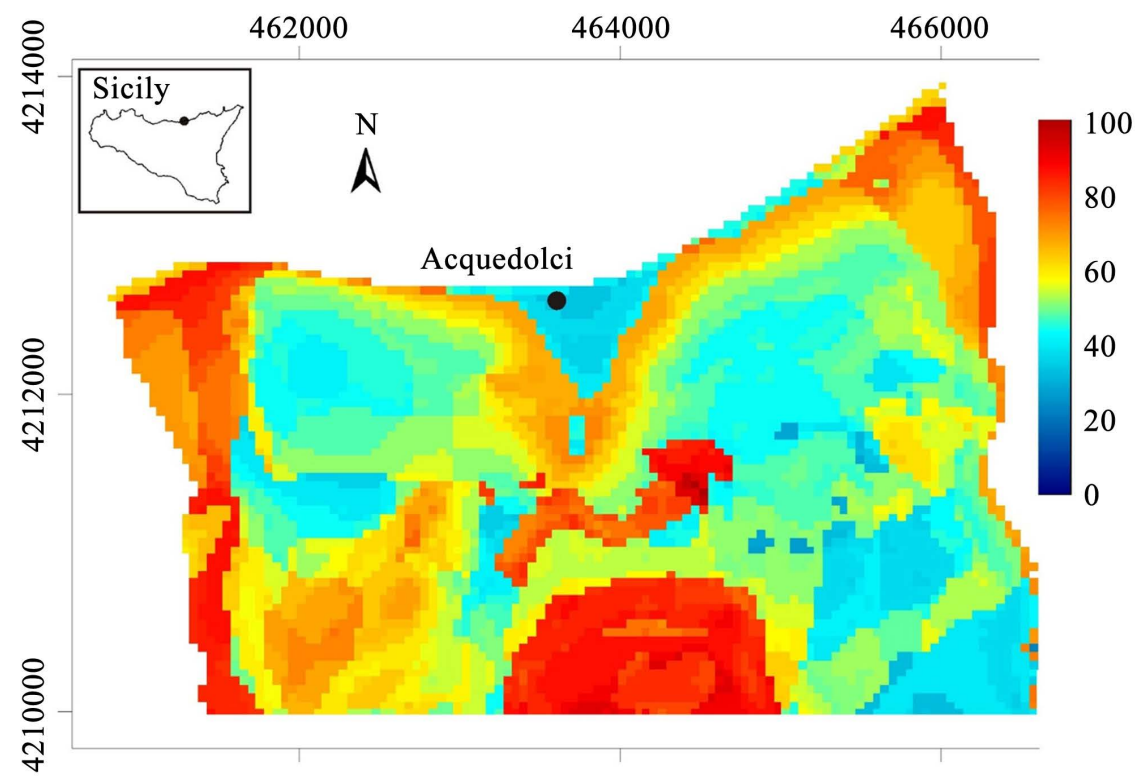

Figure 2. Groundwater vulnerability map of the Acquedolci plain performed by the modified SINTACS method (SICS Release, relevant to four SINTACS selected parameters: Depth to water, Net recharge, Hydraulic conductivity, Slope).

\section{The Fuzzy Logic System Approach}

\subsection{Fuzzy Logic Implementation of Vulnerability Mapping}

In order to attain the proposed goals, authors have utilized a fuzzy logic routine relevant to the MathLab software (MathWorks Inc., 2003) (also for the following). In the synoptic scheme of Figure 3, it is quoted the most commonly applied fuzzy methodology, which is the Mamdani inference engine (Mamdani \& Assilian, 1975). Flowchart in Figure 4 summarizes the whole applied fuzzy logic project, showing the phases followed in this paper up to the evaluation of the results.

Here the fuzzy approach allows us to interpret the quoted problems of ambiguity originating from the standard application of contamination vulnerability assessment as SINTACS, including its modifications. This is done taking into account the natural stochastic variability of chemical-physical factors, the high background noise levels and the errors in sampling and measuring works.

So, authors have realized, through the software MATLAB ${ }^{\mathrm{TM}}$ Fuzzy Logic Toolbox, a developed evaluation system that reaches to emulate the expert knowledge, taking into account empirical and subjective elements, usually neglected, but closer to human reasoning. So, the main difficulty generally presented by the complex field of the aquifer contamination risk, where non-linear and multi-dimensional elements are involved and where the hydrogeological data themselves are often intrinsically vague and uncertain, can be overcome. Furthermore, it is essential to accurately define and analyze the system variables and their intrinsic role, fixing inputs and outputs. Input features are defined by the ranges of all the values assumed by any variable and membership function. It is preferred to choose Gaussian functions for the membership functions, because 


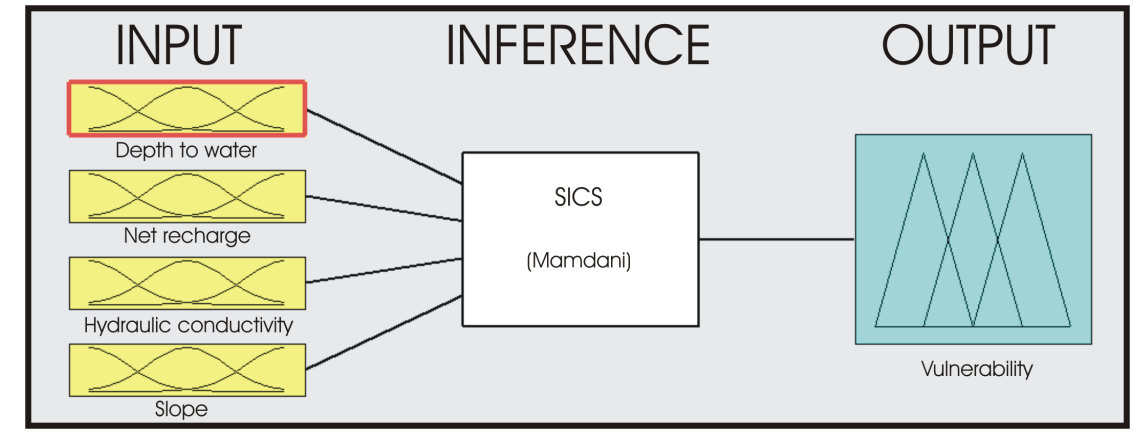

Figure 3. Synoptic scheme of the fuzzy logic structure referred to the studied system (Fuzzy Logic Toolbox). Mamdani inference engine, along with the four inputs, are here opportunely schematized (Mamdani \& Assilian, 1975).

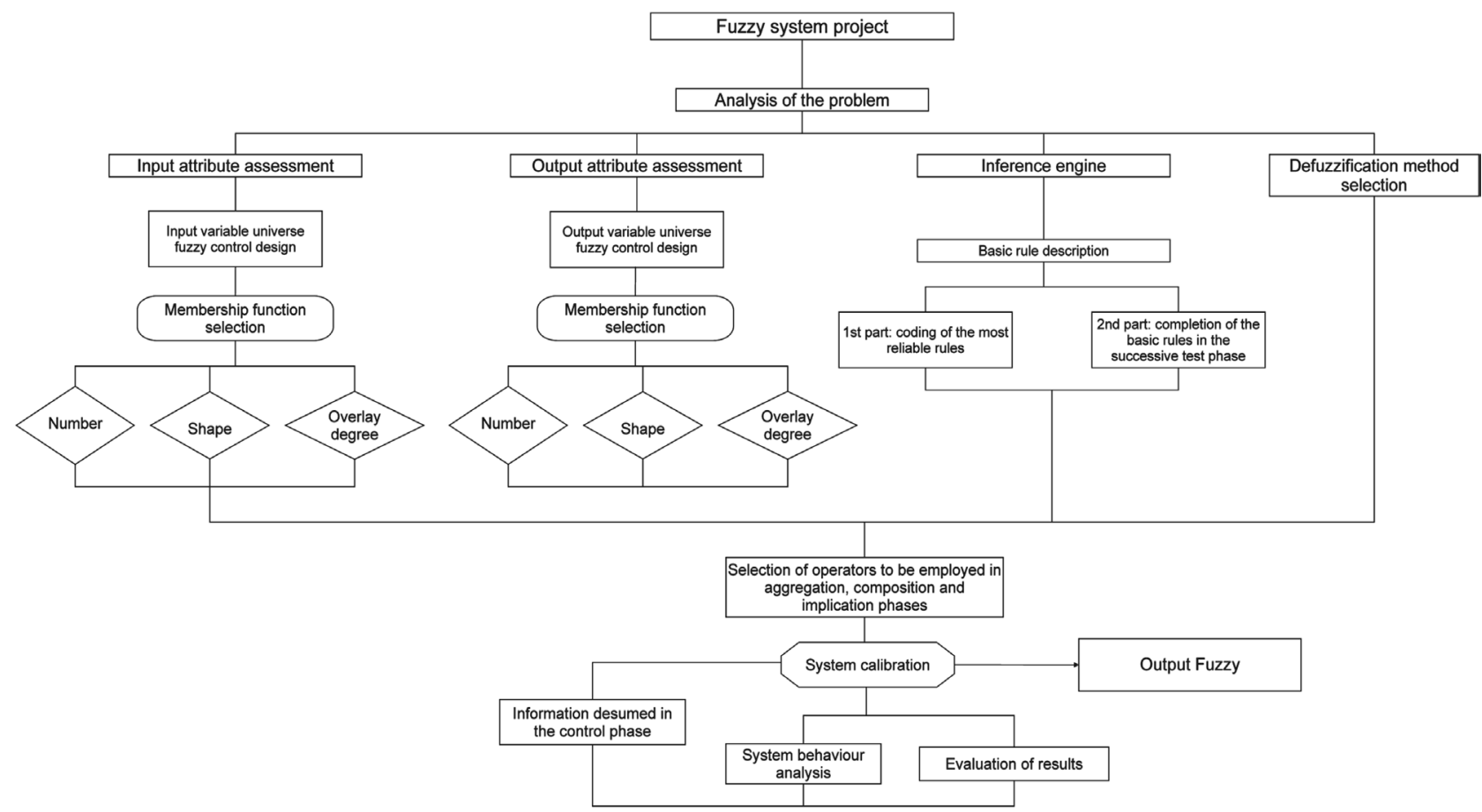

Figure 4. Flowchart of the fuzzy logic project.

they suitably emulate the human perception, offering gradual outputs. Moreover, it is very important the matching grade among the adopted membership functions, simultaneously activating more rules (Zadeh, 1965). Concerning the output variables, it is necessary to establish their existence ensemble and the eventual scale factors for the post-elaboration. Notable importance is given to the defuzzification step, which is the procedure of creating a quantifiable result in fuzzy logic with the selection of a number of rules. More in detail, here the output conversion utilizes the Centroid Average (CA) and Mean of Maximum (MOM), being this last one preferred, giving more convenient results with respect to the input data. Lastly, the inference engine particularly determines the different interaction mechanisms. The rules represent heuristic data and concepts, replying by linguistic terms the relations between input and output va- 
riables. The five used term sets represent the vulnerability grade: very low, low, medium, high and very high.

\subsection{Calibration of Fuzzy Logic System and Its Application in North Sicily}

The calibration of fuzzy logic system forecasts that membership functions, linguistic terms and rules of the inference engine are established (Zadeh, 1965) (quoted paper). In this way, it is possible to test (using appropriate MATLAB tools as the Surface View) the dependence between outputs and inputs, eventually modifying them. The rules applied in the Acquedolci area (see again Figure 3) represent heuristic data and concepts, expressing with linguistic terms the relations between input and output variables. In this case, the used vulnerability grades are represented by five term sets: Very low, low, medium, high and very high, here referred to a limited number of SINTACS parameters (Depth to water, Net recharge, Hydraulic conductivity, Slope, see again Figure 2). Applying fuzzy logic, a further set of vulnerability maps was elaborated, with the same group of parameters, and Figure 5 exhibits the product of this elaboration, which is the $A c$ quedolci fuzzy-logic vulnerability map. By comparing this map with the previous SICS elaboration, resulted from the standard point-count system procedure, notable differences are clearly shown in the vulnerability classification, as in the inland part of the plain, evidencing weaker zones previously considered less vulnerable.

Once that membership functions, linguistic terms and rules of the inference engine are established (the system project), it is now possible to test (using appropriate MATLAB tools as the Surface View) the dependence between outputs and inputs, eventually modifying them. Regarding the application to contamination vulnerability of aquifers, the adopted system for its simplicity and comprehensibility appears to be clearly advantageous as respect to other standard available

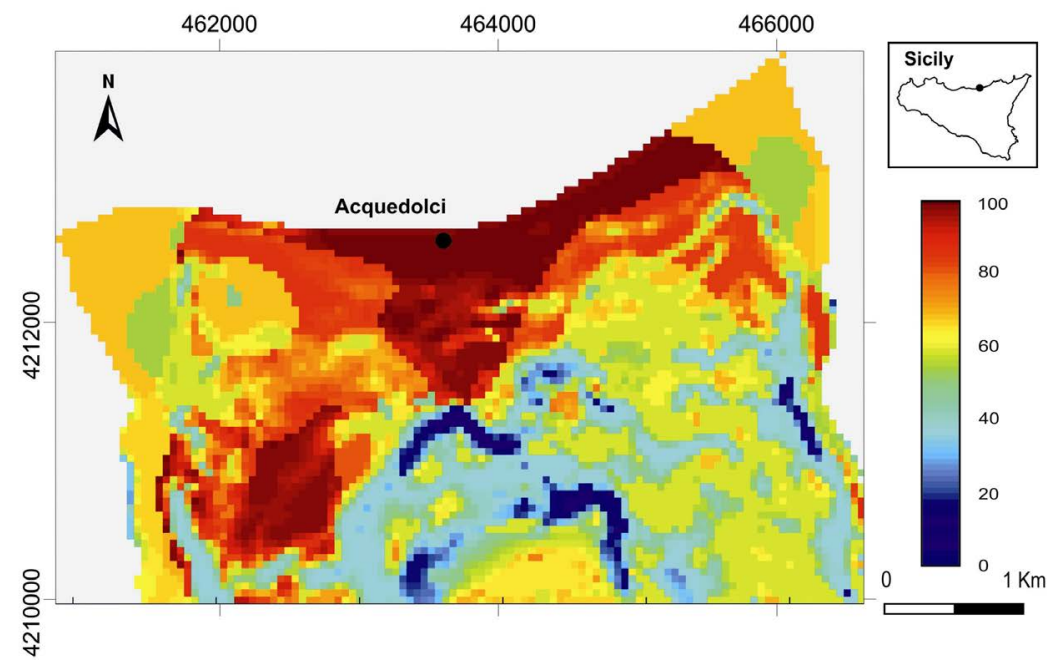

Figure 5. Acquedolci fuzzy-logic map (SICS, four SINTACS parameters: Depth to water, Net recharge, Hydraulic conductivity, Slope). 
models (SINTACS). This permits the users to easily monitor the whole procedure with a proper awareness of the system efficiency.

As quoted above, the Acquedolci plain has been continuously surveyed by several studies of its hydrogeological features, integrated with geophysical and geochemical measures, with particular regards to the contamination vulnerability of aquifers. In successive steps, these pieces of information permitted to perform a set of contamination risk maps relevant to the aquifers of the plain. According to the selected SINTACS parameters, a further set of SICS vulnerability maps was elaborated, with the same group of four parameters (Depth to water, Net recharge, Hydraulic conductivity, Slope) and applying the fuzzy logic. Figure 5 exhibits the final outcome of this elaboration, which is the Acquedolci fuzzy-logic map, resulting from the application of the procedure above explained. Comparing this map with the previous SICS elaboration (see again Figure 2), resulted from the modified SINTACS procedure, it clearly shows notable differences in the vulnerability classification, mainly in the inland part of the plain. Both maps have been reclassified into vulnerability categories from 0 to 100, permitting the best comparison. Fuzzy map appears to look quite different, permitting refined zoning of vulnerability and constituting a useful tool of territory planning.

All the individual parameters, as used in the SICS analysis, sensibly affect the final result shown in Figure 5. Their single improvement in fuzzy logic procedure is evidenced by the corresponding partial analyses. In this paper, authors have proposed fuzzy logic approach as an improvement to the SICS method. But it is necessary to give further pieces of information about the contribution of each single parameter to the last map. First of all, it has to be considered that the studied Acquedolci region offers, as shown in the geologic description, a singular geomorphological variety.

In few hundreds of meters, landscape and geology exhibit very different aspects, as flat arenaceous territories in the very peopled coastal zones, and steep karst relieves in southern part, with scarce form of urbanization (see again Figure 1). In these extreme conditions, classical methods (SINTACS or SICS) cannot fully represent the real vulnerability to contamination. All SICS parameters are very likely involved in the improvement of vulnerability procedure. The heavy anthropization and contamination of the Acquedolci territory produce a significant influence in Depth to water and Slope parameters. On the other hand, the deep alteration of upper portions of aquifer, due to intensive cultivation and soil use, plays an important role in Net recharge and Hydraulic Conductivity. Thus, the comparison between SICS and Fuzzy-SICS vulnerability elaborations (Figure 2 and Figure 5), makes it possible to observe a larger extension of criticism in coastal areas in the fuzzy enhancement process. On the other hand, for opposite reasons, in limestone zones, vulnerability appears to be lower. Enhancement in western and eastern portions of the territory, where impervious covering is diffuse, regards a general increase of vulnerability, except for limited belts. 


\section{Conclusive Considerations}

This paper showed an implementation of contamination vulnerability assessment in an area of Sicily where aquifers constitute true complex natural systems. This is caused by the diffuse anisotropy of hydrogeological parameters in the area and by the non-linear relations between input and output data in the mapping elaboration procedure. The efforts to test fuzzy logic application in this complicated area allowed us to better depict the vulnerability conditions of aquifers, closely influenced by deterministic and stochastic phenomena.

Statistical ways to further improvements of aquifer risk and vulnerability setting can be given by comparing the different outcomes (maps as well as vulnerability class zoning) with the real quality degradation of groundwater, also applying suitable modifications to the known systems, for example, the quoted DRASTIC and SINTACS. At this proposal, fuzzy logic certainly represents a very useful approach in mitigating uncertainties and subjectivities, simplifying the decisions about number and type of parameters. It contributes to overcoming certain difficulties in the complex field of contamination risk assessment, where non-linear and multi-dimensional elements are involved and the hydrogeological data themselves are intrinsically vague and uncertain (Woldt et al., 1996).

Finally, fuzzy logic advantages in risk contamination assessment can be summarized as follows:

1) Capability to perform non-linear models and to favourably treat doubtful and unconvinced data;

2) Flexibility in erasing and/or adding rules and in using points and weights in order to assign different importance to variables;

3) Conceptual simplicity and good matching with the human way of thinking (Kosko, 1993). The efforts to test fuzzy logic application in the studied area allowed us to better depict the vulnerability conditions of aquifers, closely influenced by deterministic and stochastic phenomena.

\section{Acknowledgements}

The authors thank the colleagues of Physics Department of University of Palermo and, in particular, Prof. Francesco Fauci, colleague and first of all friend, for his encouragement in the application of statistical methods to hydrogeology. A dutiful appreciation goes to the Italian Ministry of University and Research for having funded the research to which this work belongs.

\section{Conflicts of Interest}

The authors declare no conflicts of interest regarding the publication of this paper.

\section{References}

Abdullah T. O., Ali, S. S., Al-Ansari, N. A., \& Knutsson, S. (2017). Vulnerability of Groundwater to Pollution Using Three Different Models in Halabja Saidsadiq Basin, 
Iraq. European Water, 57, 353-359. https://doi.org/10.1016/j.gsd.2019.100276

Aller, L., Bennet, T., Lehr, J. H., Petty, R. J., \& Hackett, G. (1987). DRASTIC. A Standardized System for Evaluating Groundwater Pollution Potential Using Hydrogeological Settings (p. 163). EPA 600/2-85/018, North Wales Water Authority.

Baalousha, H. M. (2010). Mapping Groundwater Contamination Risk Using GIS and Groundwater Modelling. A Case Study from the Gaza Strip, Palestine. Arabian Journal of Geosciences, 4, 483-494. https://doi.org/10.1007/s12517-010-0135-0

Cameron, E., \& Peloso, G., F. (2005). Risk Management and the Precautionary Principle: A Fuzzy Logic Model. Risk Analysis, 25, 901-912. https://doi.org/10.1111/j.1539-6924.2005.00607.x

Cimino, A. (2005). New Cartographic Contributions in the Contamination Vulnerability Assessment of Coastal Aquifers in Sicily. Epitome, 1, 263-264.

Cimino, A., Corniello, A., Ducci, D., \& Oieni, A. (2010). Analysis of the Possibility of Parameters Reduction in SINTACS Method (Abstract Volume I, pp. 161-162). Rendiconti Online della Società Geologica Italiana.

Cimino, A., Cosentino, C., Oieni, A., \& Tranchina, L. (2008). A Geophysical and Geochemical Approach for Seawater Intrusion Assessment in the Acquedolci Coastal Aquifer (Northern Sicily). Environmental Geology, 55, Article No. 1473. https://doi.org/10.1007/s00254-007-1097-8

Cimino, A., Lo Brutto, M., Martorana, R., \& Sciortino, A. (2000). Groundwater Quality and Aquifer Vulnerability in the Metropolitan Area of Palermo. Memorie della Società Geologica Italiana, 55, 463-471.

Civita, M., \& De Maio, M. (2000). Valutazione e cartografia automatica della vulnerabilità degli acquiferi all'inquinamento con il sistema parametrico SINTACS R5 (226 p.). Pitagora.

Di Martino, F., Sessa, S., \& Loia, V. (2005). A Fuzzy-Based Tool for Modelization and Analysis of the Vulnerability of Aquifers: A Case Study. International Journal of Approximate Reasoning, 38, 99-111. https://doi.org/10.1016/j.ijar.2004.05.001

Ducci, D. (2010). Aquifer Vulnerability Assessment Methods: The Non-Independence of Parameters Problem. Journal of Water Resource and Protection, 2, 298-308. https://doi.org/10.4236/jwarp.2010.24034

Kosko, B. (1993). Fuzzy Thinking: The New Science of Fuzzy Logic (318 p.). Hyperion Books.

Mamdani, E. H., \& Assilian, S. (1975). An Experiment in Linguistic Synthesis with a Fuzzy Logic Controller. International Journal of Man-Machine Studies, 7, 1-13. https://doi.org/10.1016/S0020-7373(75)80002-2

MathWorks Inc. (2003). MATLAB Fuzzy Logic ToolBox ${ }^{T x}$, Users Guide(323 p.). MathWorks Inc.

Panagopoulos, G. P., Antonakos, A. K., \& Lambrakis, N. J. (2006). Optimization of the DRASTIC Method for Groundwater Vulnerability Assessment via the Use of Simple Statistical Methods and GIS. Hydrogeology Journal, 14, 894-911. https://doi.org/10.1007/s10040-005-0008-x

Woldt, W., Dahab, M., Bogardi, I., \& Dou, C. (1996). Management of Diffuse Pollution in Groundwater under Imprecise Conditions Using Fuzzy Models. Water Science Technology, 33, 249-257. https://doi.org/10.2166/wst.1996.0512

Wu, J., \& David, J. L. (2002). A Spatially Explicit Hierarchical Approach to Modeling Complex Ecological Systems: Theory and Applications. Ecological Modelling, 153, 7-26. https://doi.org/10.1016/S0304-3800(01)00499-9

Zadeh, L. A. (1965). Fuzzy Sets. Information and Control, 8, 338-353. 
https://doi.org/10.1016/S0019-9958(65)90241-X

Zuquette, L. V., Palma, J. B., \& Pejon, O. J. (2009). Methodology to Assess Groundwater Pollution Conditions (Current and Pre-Disposition) in the São Carlos and Ribeirão Preto Regions, Brazil. Bulletin of Engineering Geology and the Environment, 68, 117-136. https://doi.org/10.1007/s10064-008-0173-y 